\title{
Estimates of phenotypic diversity and genetic parameters of Hibiscus cannabinus L. grown in Burkina Faso
}

\author{
Nikodème V. KABRÉ*, Boureima SAWADOGO, Mariam KIÉBRÉ, Zakaria KIÉBRÉ, \\ Romaric K. NANEMA and Pauline BATIONO-KANDO
}

Equipe de Recherche de Génétique et Amélioration des Plantes, Laboratoire Biosciences, Unité de Formation et de Recherche en Sciences de la Vie et de la Terre, Université Joseph KI-ZERBO, 03 BP 7021 Ouagadougou 03.

*Corresponding author; E-mail: kabrenicodeme@yahoo.fr/ boureimasawadogo19@yahoo.fr;

$$
\text { Tel.: (+226) } 73640494 \text { /(+226) } 78729182 \text {. }
$$

\begin{abstract}
Hibiscus cannabinus is a traditional leafy-vegetable consumed more and more in Burkina Faso. Its leaves and fruits are some good food supplement against nutritional deficiencies. Its fibers are also a source of income for households. Despite of its nutritional an economic potential, this species is underdeveloped in Burkina Faso. The study aims to determine genetic variability and level of heritability among agronomic interest traits of $H$. cannabinus using agro-morphological descriptors. This enable to identify outstanding accessions which could be involved in further breeding programs. A total of 70 accessions of $H$. cannabinus were characterized according randomized incomplete block, using 5 qualitative characters and 15 quantitative characters. The study showed great variability for most of the qualitative and quantitative characteristics studied. Several correlations were observed between characters related to the biomass, the fruits and the fibers production. These correlations are particularly interesting because the improvement of only one character induces improvement of the others. The study, moreover, shows high broad sense heritability $\left(\mathrm{H}^{2}\right)$ and weak differences between the phenotypic (PCV) and genotypic (GCV) coefficients of variation. These results indicate that the characters expression is under genetic control. So a direct selection method of H. cannabinus improvement is possible for these characters.
\end{abstract}

(C) 2019 International Formulae Group. All rights reserved

Keywords: Agromorphological, characterization, Hibiscus, selection, Burkina Faso.

\section{INTRODUCTION}

Hibiscus cannabinus is a species of multiple uses in Burkina Faso through its organs of interest such as the leaves, the fibers and the seeds. The leaves are cooked as sauce, because they have properties of digestive ballast and intestinal purifier (MillogoRasolodimby, 2001). They are used as a medicine to purge, to treat diarrhea, hypertension, dysentery and bilious unrest (Bermudez-Soto et al., 2007). The seeds are used for the manufacturing of a local condiment, named "soumbala" in dioula, "Bicalga" in mooré and "gio-sola" in GurunsiLélé. This condiment is even considered tastier than the soumbala (another traditional condiment) made on the basis of Vitelaria paradoxa seeds. The fibers are used in ropes manufacturing, masks manufacturing called "biiddu" and in funeral rituals to make the cadavers ready for burial. The aqueous excerpts and methanolic of the seeds are used 
as antioxidants. Regarding its socio-economic importance, $\mathrm{H}$. cannabinus is an indispensable resource for the local populations. However, it is neglected by research because few investigations have been dedicated to it. So, its potential is under-exploited by the population and its genetic varieties are still less known. Some studies of the agromorphological diversity were carried out in East Africa, notably in Kenya, Tanzania and Malawi. Its diversity was studied in West Africa especially in Nigeria, where the species is well-known and cultivated as a plant having commercial fibers (Lakshmana et al., 2009). In Burkina Faso, the studies that have already been done are only focused on the tenacity of its fiber and on the traditional knowledge and expertise about the management of the species (Kabré et al., 2017). For the need of documentation of this species in Burkina Faso, the current study was initiated and aimed at characterizing the genetic variability of $H$. cannabinus. Its basic objectives are to (i) identify the agro-morphological characters that discriminate $H$. cannabinus genotypes, (ii) establish the relations which exist between them, and (iii) estimate genetic parameters in a collection of $H$. cannabinus accessions of Burkina Faso, such as broad sense heritability $\left(\mathrm{H}^{2}\right)$, genotypic $(\mathrm{GCV})$ and phenotypic (PCV) coefficient of variation and genetic advance (GA) expected from selection.

\section{MATERIALS AND METHODS \\ Materials \\ Genetic material}

Seventy (70) accessions of $H$. cannabinus were randomly collected in fiftysix (56) villages distributed into seven (7) provinces (Table 1) of the three climatic zones of Burkina Faso (Figure 1).

\section{Experimental site}

A trial was conducted at "Institut du Développement Rural" (an agronomic research center) located at Gampela $\left(1^{\circ} 21^{\prime} 9\right.$, $6^{\prime \prime} \mathrm{W} ; 12^{\circ} 24^{\prime} \quad 29^{\prime \prime} \mathrm{N}$ ) in Ouagadougou. Gampela is located precisely in the NorthSudanian zone with an annual rainfall ranging from 600 to $900 \mathrm{~mm}$ (Thiombiano \& Kampmann, 2010). Rainfall patterns recorded during 2017 rainy season was $677.1 \mathrm{~mm}$ of water between May and October. The test was implanted on a sand-clay soil with a water $\mathrm{pH}$ of 5.20. The analysis of this soil shows that it is composed of total nitrogen (0.046 $0.071 \%)$, phosphate $(9.71-10.91 \mathrm{ppm})$ and potassium $(84.18-101.23 \mathrm{ppm})$.

\section{Methods}

\section{Experimental design}

The experimental design consists of a randomized incomplete block with threerepeat. One meter distance separated the blocks. Each block then was subdivided into two (02) elementary blocks that are spaced also by one meter $(1 \mathrm{~m})$ distance. As far as sowing is concerned, each seed hole was spaced by a $0.6 \mathrm{~m}$ distance on a $4.2 \mathrm{~m}$ long line and lines were separated by $0.8 \mathrm{~m}$ space.

\section{Observed variables}

Twenty (20) variables including fifteen (15) quantitative and five (05) qualitative derived from $H$. cannabinus descriptor of the National Office of Genetic Resources Plantation have been valued. All the observations and measurements were made 80 days after sowing date, corresponding to the $50 \%$ flowering stage, at four plants per line and per accession. The number of days $50 \%$ flowering (DFL) has been valued on the whole line. Qualitative traits include stem color (COT), ribs color (CNE), petal color (CPE), shape of the leaves (FFE) and the pubescence of the stems (PTI). Quantitative traits measured are plant height (HPL), stem diameter (DIT), dry fibers weight (PFI), petiole length (LPE), limb length (LOL), limb width (LAL), leaves biomass (PFF), petal length (LOP), petal width (LAP), Number of sepal (NSE), length and diameter of the fruit respectively (LFR) and (DFR), number of fruits (NFR) and 100 seeds weight (PCG).

\section{Data analysis}

The descriptive analysis has been made using qualitative data. Thus, some frequencies have been calculated and the diagrams constructed from the frequencies we had. The quantitative data were used for variance (ANOVA) using the GenStat v4.10.3 software to determine those discriminate accessions. Correlations between these traits were studied using Pearson correlation tests (1\% level). 
Principal component analysis (PCA) was performed to know the associations between the studied characters. All the accessions were consecutively grouped from the hierarchical ascending classification (CAH) based on the segregation of Ward method based on using Euclidean distance between individuals. The genotypic and phenotypic variances
(VG\&VP), the phenotypic and genotypic coefficients of variations (PCV\&GCV), the heritability $\left(\mathrm{H}^{2}\right)$, the genetic advance $(\mathrm{GAx})$, formulas proposed by Johnson et al. (1955); Assefa et al. (2001) and Hosseini et al. (2012) have been used (Table 2). Excel, XLstat 7.5.2 and Genstat v4.10.3 software, have been used for these analyses.

Table 1: Distribution of the producers according to province and sex.

\begin{tabular}{lccc}
\hline $\begin{array}{l}\text { Provinces of } \\
\text { collection }\end{array}$ & Number of producers & Proportions of men (\%) & Proportions of women (\%) \\
\hline Kadiogo & 9 & 75 & 25 \\
Kouritenga & 25 & 78 & 22 \\
Nahouri & 29 & 60 & 40 \\
Oubritenga & 11 & 82 & 18 \\
Sanguié & 19 & 75 & 25 \\
Sissili & 18 & 50 & 50 \\
Yatenga & 4 & 68 & 32 \\
\hline
\end{tabular}

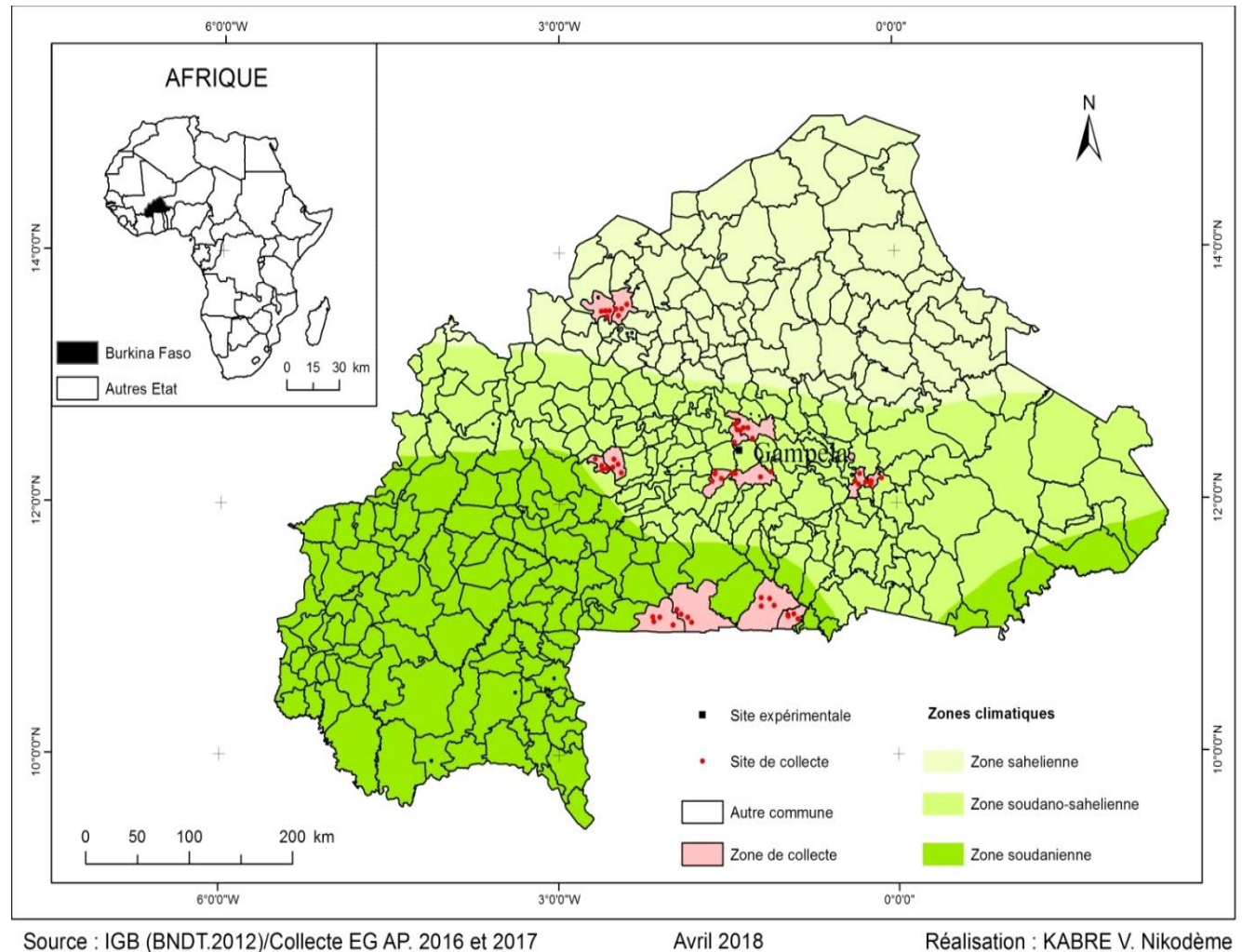

Figure 1: Localization of prospecting-collection zones of Hibiscus cannabinus accessions. 
Table 2: Formula used for the estimates of the genetic parameters

\begin{tabular}{lll}
\hline $\mathbf{N}^{\circ}$ & Parameters & Formula used \\
\hline 1 & Genotypic Variance (VG) & $\mathrm{VG}=(\mathrm{MSG}-\mathrm{MSE}) / \mathrm{r}$ \\
2 & Phenotypic Variance (VP) & $\mathrm{VP}=\mathrm{VG}+(\mathrm{MSE} / \mathrm{r})=\mathrm{MSG} / \mathrm{r}$ \\
3 & Broad sense heritability $\left(\mathrm{H}^{2}\right)$ & $\mathrm{H}^{2}(\%)=(\mathrm{VG} / \mathrm{VP}) * 100$ \\
4 & Genotypic coefficient of variation $(\mathrm{GCV})$ & $\mathrm{GCV}(\%)=\left(\sigma_{\mathrm{G}} / \mathrm{X}\right) * 100$ \\
5 & Phenotypic coefficient of variation $(\mathrm{PCV})$ & $\mathrm{PCV}(\%)=\left(\sigma_{\mathrm{P}} / \mathrm{X}\right) * 100$ \\
6 & Genetic advance $(\mathrm{GA})$ & $\mathrm{GA}=\mathrm{H}^{2} \sigma_{\mathrm{P}} \mathrm{K}$ \\
7 & $\mathrm{GA}(\%$ of trait mean) $[\mathrm{GAx}(\%)]$ & $\mathrm{GAx}(\%)=(\mathrm{GA} /$ trait mean $) * 100$ \\
\hline
\end{tabular}

$\mathrm{MS}_{\mathrm{G}}$ is the means squared of genotype, $\mathrm{MS}_{\mathrm{E}}$ is the means squared of the residual (error), and $\mathrm{r}$ is the number of replication, $\sigma_{\mathrm{G}}$ is the genotypic standard deviation, $\sigma_{\mathrm{P}}$ is the phonotypic standard deviation, $\mathrm{X}$ is the trait mean; $\mathrm{K}$ is a constant, which at the selection intensity of $5 \%$ is 2.06 .

\section{RESULTS}

Agro-morphological variation related to the qualitative traits of Hibiscus cannabinus

All accessions of $H$. cannabinus collection have pubescent leaves and fruits. The stems are more pubescent than the leaves. Indeed $27.14 \%$ of accessions collected have stems deprived of pubescence compared to $72.86 \%$ of stems having epidermal hairs. Meanwhile a high variability has been observed for the other characters (Table 3). This variability is mainly perceptible on the color of the different organs. Thus the stems present 6 colors (Figure 2) such as green (57.14\%), purple $(22.86 \%)$, violet $(7.14 \%)$, black (5.71\%), red (4.29\%) and green speckled $(2.86 \%)$. The leaves are alternate, with a simple serrated or serrated-lanceolate or finger-lobed limb with veins and petioles generally of the same color as the stem.

\section{Agro-morphological variation related to the quantitative traits of Hibiscus cannabinus}

Analysis of variance reveals a highly significant difference between accessions ( $\mathrm{p}$ $<0.0001$ ) at $1 \%$ levels (Table 4). The coefficients of variation of the majority of the studied characters are low $(\mathrm{CV}<30 \%)$. That shows a low heterogeneity of plant material for these characters. However, they are high $(\mathrm{CV}>30 \%)$ for fruits number $(\mathrm{CV}=31.52 \%)$ and leaves biomass $(\mathrm{CV}=71.25 \%)$. That indicates a high heterogeneity of studied accessions for these characters. The accessions of $H$. cannabinus flower between
59 and 96 days after having $2.7 \mathrm{~m}$ height. Full bloom flowers (5 petals) occur between 7 and 10 days after button floral shaping. Fruits occur after petals fall that is 2 and 3 days after their emergence. The majority of accessions had leaves having long petiole (12.5 to 28.12 $\mathrm{cm})$ and a limb having a less varied length and width $(1.85<\mathrm{ET}<1.91 \mathrm{~cm})$. A high variability between accessions has been observed regarding the number of fruit per plant $(\mathrm{ET}=13)$, the weight of dry fibers $(\mathrm{ET}=14.05 \mathrm{~g})$ and the leaves biomass $(\mathrm{ET}=397.5 \mathrm{~g})$.

\section{Correlation between the studied traits}

Table 5 displays many positive and highly significant correlations obtained at $\alpha=$ $1 \%$. The most important ones are those observed between plant height and stem diameter $(\mathrm{r}=0.471)$, dry fibers weight $(\mathrm{r}=$ $0.310)$; number of fruits and stem diameter $(r$ $=0.252)$, dry fibers weight $(r=0.328)$ and leaves biomass $(r=0.604)$ as well as between number of days $50 \%$ flowering and fruit diameter $(r=0.421)$; between length of fruit and weight of 100 seeds $(r=0.322)$. The most significant negative correlations are observed between days $50 \%$ flowering and number of fruits per plant $(\mathrm{r}=-0.235)$, length of fruit $(\mathrm{r}=$ -0.470), 100 seeds weight $(r=-0.482)$ and leaves parameters. There are also negative correlations between leaves biomass and fruits diameter $(r=-0.277)$ and finally between fruit diameter and number of fruits $(r=-0.361)$, length of fruit $(r=-0.248)$. 


\section{Associations of morphological traits}

The total variability expressed by the first three axes is $55.413 \%$ (Table 6). Axis 1 expresses $26.890 \%$ of this total variability. Seven characters contribute the most to achievement of axis 1 . These are variables number of days $50 \%$ flowering $(\mathrm{r}=0.667)$, number of fruits $(r=0.250)$, petal length $(r=$ $0.670)$, number of sepals $(r=0.194)$, length of fruit $(r=0.403)$, fruit diameter $(r=0.386)$ and 100 seeds weight $(r=0.374)$. This axis characterises the accessions of $H$. cannabinus having a long flowering cycle; producing long and heavy fruits and containing numerous and heavy seeds. Axis 2 which expresses $15.749 \%$ of this total variability is positively correlated to petiole length $(r=0.315)$, plant height $(r=$ $0.327)$ and stem diameter $(r=0.641)$. This axis gathers accessions which have an important vegetative development. At last, axis 3 expresses $12.773 \%$ of this total variability and is correlated to limb length $(\mathrm{r}=$ $0.295)$ and leaves biomass $(r=0.314)$.

\section{Structuring the diversity of studied accessions}

The dendrogram resulting from the hierarchical ascending classification $(\mathrm{CAH})$ of Figure 3 reveals a distribution of the 70 accessions in 3 groups. This variability depends more on genotypes than the origin of accessions. An examination of the coefficient of determination and Fisher's F statistic values indicates that five characters such as cycle of flowering $\left(\mathrm{R}^{2}=3.5 \%\right)$, number of fruits $\left(\mathrm{R}^{2}=\right.$ $54.1 \%)$, fruit diameter $\left(\mathrm{R}^{2}=4.4 \%\right), 100$ seeds weight $\left(\mathrm{R}^{2}=4.7 \%\right)$ and leaves biomass $\left(\mathrm{R}^{2}=\right.$ $97.5 \%$ ) with a p-value $<0.0001$ are more discriminating of the 3 agromorphological groups obtained. That shows that they are very distinct. These results are confirmed by the Newmann Keuls test (Table 7). So, group 1 consists of 30 accessions (43\% of all collected accessions). These accessions come from 7 provinces. This group is characterized by accessions having long flowering cycle (80.52 days). They produce high diameter fruit $(1.59 \mathrm{~cm})$ and low biomass leave (577.02g). Group 2 includes 26 accessions (37\% of accessions collected) come from 5 provinces belonging to the Sudanian and Sudano-Sahelian zone. This group is characterized by accessions having precocious cycle (76.36 days) and producing many fruits (83.21) having mean diameter $(1.50 \mathrm{~cm})$ but 100 seeds weight most elevated. At last, group 3 includes 14 accessions (20\% of collected accessions) coming from 4 provinces distributed in three climatic zones of the country as group 1. This group is characterized by accessions having intermediate cycle (78.85 days) between group 1 and group 2 producing as group 2, a lot of fruits (85.33), heavy seeds $(2.97 \mathrm{~g})$. It produces the most high leaves biomass (3946.34 g).

\section{Estimates of Genetic the Parameters of Hibiscus cannabinus}

The heritability is high $\left(\mathrm{H}^{2}>80 \%\right)$ for the number of days $50 \%$ flowering, number of fruits, 100 seeds weight, dry fibers weight and leaves biomass. It is moderate for the other characters except petal width where it is low. Phenotypic variances are higher than genotypic variances for all studied characters (Table 8). Phenotypic variances varied from 0.01 to 1277949.33 and genotypic variances from 0 to 1275258 . The leaves biomass, the number of fruit, the dry fibers weight and the number of days $50 \%$ flowering have very high genotypic and phenotypic variance values. But it is very low $(<01)$ for other studied characters. The phenotypic coefficients of variation are higher than the genotypic coefficients of variation for all studied characters. The maximal gap $(11.03 \%)$ is obtained for the character "fruit length" (PCV $=14.71 \%$ and $\mathrm{GCV}=3.68 \%$ ). The characters, leaves biomass, number of fruits and dry fiber weights had at a time elevated PCV and GCV $(>20 \%)$. Characters such as DFL, LPE, NSE, DFR, had low $(<11 \%)$. All the other characters have moderate PCV $(>20)$. The genetic advance (GAx) varied from $0.11 \%$ (petal width) to $146.43 \%$ (leaves biomass). The characters of interest such as leaves biomass, number of fruits, dry fibers weight and 100 seeds weight record the most elevated genetic advance compared to the other characters. The flowering cycle, the length and the width of the limb had genetic moderate advance $(18.34 \%, 14.67 \%$, and $12.45 \%$ respectively). 
Table 3: Variation of the qualitative characters in the collection of $H$. cannabinus

\begin{tabular}{lll}
\hline Characters & Modalities & Frequencies $(\%)$ \\
\hline \multirow{4}{*}{ COT } & Black & 5,71 \\
& Purple & 22,86 \\
& Red & 4,29 \\
& Green & 57,14 \\
& Green speckled & 2,86 \\
& Violet & 7,14 \\
\hline \multirow{4}{*}{ CPE } & Black & 5,71 \\
& Purple & 25,71 \\
& Red & 7,14 \\
& Green & 57,15 \\
PTI & Violet & 4,29 \\
\hline \multirow{3}{*}{ CNE } & Black & 5,71 \\
& Purple & 25,71 \\
& Red & 7,14 \\
& Green & 57,15 \\
& Violet & 4,29 \\
\hline & Simple jagged & 88,57 \\
& Jagged lanceolate & 4,29 \\
& palmate polylobe & 7,14 \\
\hline & No pubescent & 27,14 \\
& Pubescent & 72,86 \\
\hline
\end{tabular}

Stem color (COT), petiole color (CPE), rib color (CNE), leaves shape (FFE), stem pubescence (PTI).
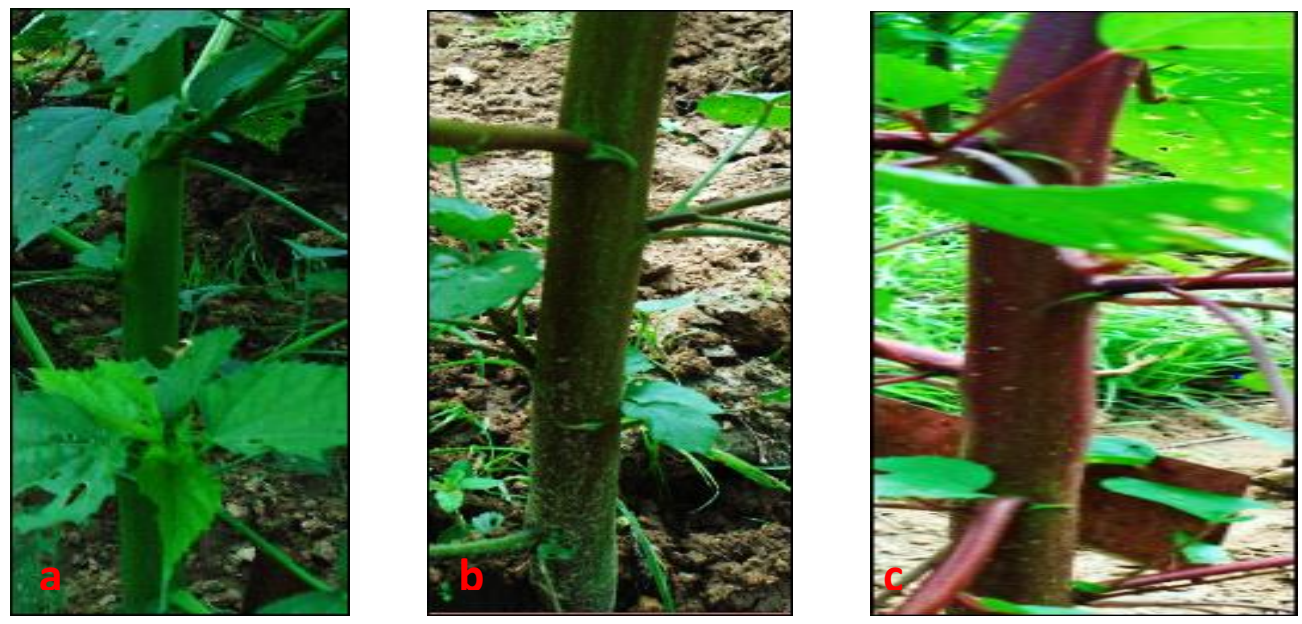

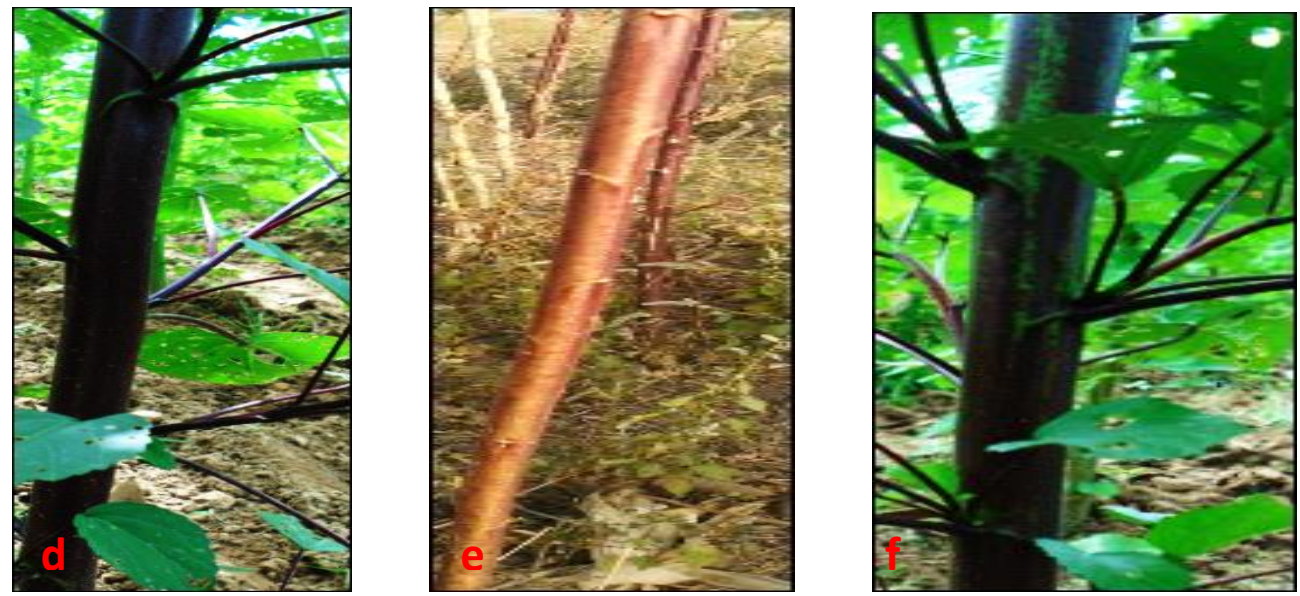

a. green stem; b. purple stem; c. violet stem; d. black stem; e. red stem; f. speckled green stem

Figure 2: H. cannabinus stem colors.

Table 4: Performance of the 70 accessions for the different quantitative traits and F Fisher observed as well as their.

\begin{tabular}{|c|c|c|c|c|c|c|c|c|}
\hline Variables & Minimum & Maximum & Mean & ET & $\mathrm{CV}(\%)$ & $\mathbf{R}^{2}(\%)$ & F value & $\operatorname{Pr}>F$ \\
\hline DFL (day) & 59 & 96 & 78.65 & 10.03 & 12.75 & 37.86 & $118.64 * *$ & $<0.0001$ \\
\hline NFR & 21 & 93.5 & 52.11 & 12.94 & 31.52 & 14.65 & $33.67 * *$ & $<0.0001$ \\
\hline LPE (cm) & 12.5 & 28.12 & 19.75 & 2.78 & 14.10 & 11.68 & $71.92 * *$ & $<0.0001$ \\
\hline LOL (cm) & 2.87 & 18.12 & 14.14 & 1.85 & 13.09 & 9.42 & $76.84 * *$ & $<0.0001$ \\
\hline LAL (cm) & 2.3 & 15.62 & 10.98 & 1.91 & 17.43 & 15.83 & $59.78 * *$ & $<0.0001$ \\
\hline HPL (m) & 1.37 & 8.3 & 2.70 & 0.57 & 21.34 & 20.39 & $46.55^{* *}$ & $<0.0001$ \\
\hline DIT (cm) & 1.7 & 6.12 & 3.14 & 0.68 & 21.64 & 9.59 & $38.70 * *$ & $<0.0001$ \\
\hline LOP (cm) & 3.5 & 9.37 & 6.98 & 1.14 & 16.32 & 21.70 & $68.38 * *$ & $<0.0001$ \\
\hline LAP (cm) & 2 & 8.25 & 3.81 & 0.85 & 22.39 & 20.39 & $42.66 * *$ & $<0.0001$ \\
\hline NSE & 3 & 9.25 & 7.47 & 0.70 & 9.420 & 10.24 & $10.13 * *$ & $<0.0001$ \\
\hline LFR (cm) & 1.35 & 7.07 & 2.22 & 0.55 & 24.99 & 10.76 & $30.43 * *$ & $<0.0001$ \\
\hline DFR (cm) & 0.9 & 2.17 & 1.54 & 0.20 & 12.98 & 9.70 & $80.91 * *$ & $<0.0001$ \\
\hline PCG (g) & 1.4 & 3.80 & 2.86 & 0.41 & 14.62 & 51.73 & $118.22 * *$ & $<0.0001$ \\
\hline PFI (g) & 25.6 & 125.7 & 61.59 & 14.05 & 22.81 & 60.68 & $81.67 * *$ & $<0.0001$ \\
\hline PFF (g) & 122.5 & 9175 & 1209.49 & 797.58 & 71.25 & 64.05 & $16.62 * *$ & $<0.0001$ \\
\hline
\end{tabular}

Number of days $50 \%$ flowering (DFL ); number of fruits per plant (NFR); Petiole length (LPE); Limb width (LAL), Leaf length (LOL); Plant height (HPL); Stem Diameter (DIT); Petal lenght (LOP) ; Petal width (LAP); Number of sepal (NSE); Length of fruit (LFR); Diameter of fruit (DFR); Weight of 100 seeds (PCG); Weight of dry fibers (PFI); Leaves biomass (PFF); Standard deviation (ET); CV: coefficient of variation; F : F of Fisher ; $\mathrm{R}^{2}$ : coefficient of determination ; ** Significant at $1 \%$ probability levels. 
Table 5: Correlation among some of the agromorphological traits significant at $1 \%$.

\begin{tabular}{|c|c|c|c|c|c|c|c|c|c|c|c|c|c|c|c|}
\hline CHAR. & DFL & NFR & LPE & LOL & LAL & HPL & DIT & LOP & LAP & NSE & LFR & DFR & PCG & PFI & PFF \\
\hline DFL & 1 & & & & & & & & & & & & & & \\
\hline NFR & $-0,235$ & 1 & & & & & & & & & & & & & \\
\hline LPE & 0,060 & 0,109 & 1 & & & & & & & & & & & & \\
\hline LOL & $-0,402$ & 0,000 & 0,136 & 1 & & & & & & & & & & & \\
\hline LAL & $-0,253$ & 0,053 & $\mathbf{0 , 3 2 8}$ & $\mathbf{0 , 8 1 2}$ & 1 & & & & & & & & & & \\
\hline HPL & $-0,015$ & 0,093 & 0,113 & 0,231 & $-0,033$ & 1 & & & & & & & & & \\
\hline DIT & 0,101 & 0,252 & 0,373 & 0,090 & 0,033 & 0,471 & 1 & & & & & & & & \\
\hline LOP & $-0,673$ & 0,262 & $-0,063$ & 0,341 & 0,251 & 0,028 & $-0,074$ & 1 & & & & & & & \\
\hline LAP & $-0,496$ & 0,236 & $-0,035$ & 0,248 & 0,215 & 0,041 & $-0,013$ & $\mathbf{0 , 8 1 8}$ & 1 & & & & & & \\
\hline NSE & 0,402 & $-0,136$ & 0,224 & $-0,230$ & $-0,122$ & $-0,070$ & 0,072 & $-0,179$ & $-0,183$ & 1 & & & & & \\
\hline LFR & $-0,470$ & 0,082 & 0,057 & $\mathbf{0 , 3 3 8}$ & 0,255 & 0,095 & 0,061 & 0,610 & $\mathbf{0 , 5 9 3}$ & $-0,093$ & 1 & & & & \\
\hline DFR & 0,421 & $-0,361$ & 0,024 & $-0,084$ & $-0,076$ & $-0,039$ & 0,027 & $-0,344$ & $-0,171$ & 0,345 & $-0,248$ & 1 & & & \\
\hline PCG & $-0,482$ & 0,146 & $-0,108$ & 0,214 & 0,027 & 0,169 & 0,112 & $\mathbf{0 , 5 0 8}$ & 0,473 & $-0,133$ & 0,322 & $-0,218$ & 1 & & \\
\hline PFI & $-0,047$ & $\mathbf{0 , 3 2 8}$ & $-0,035$ & 0,087 & $-0,018$ & 0,310 & 0,259 & 0,166 & 0,076 & $-0,097$ & 0,043 & $-0,270$ & 0,027 & 1 & \\
\hline PFF & $-0,113$ & 0,604 & $-0,017$ & $-0,012$ & $-0,015$ & 0,157 & 0,152 & 0,191 & 0,090 & $-0,092$ & $-0,007$ & $-0,277$ & 0,084 & 0,824 & 1 \\
\hline
\end{tabular}


Table 6: Squared Cosines of 12 Characters on three factors and total variability explained of 12.

\begin{tabular}{lccc}
\hline Characters & F1 & F2 & F3 \\
\hline DFL & $\mathbf{0 . 6 6 7}$ & 0.069 & 0.008 \\
NFR & $\mathbf{0 . 2 5 0}$ & 0.233 & 0.184 \\
LPE & 0.000 & $\mathbf{0 . 3 1 5}$ & 0.291 \\
LOL & 0.100 & 0.002 & $\mathbf{0 . 2 9 5}$ \\
HPL & 0.030 & $\mathbf{0 . 3 2 7}$ & 0.004 \\
DIT & 0.007 & $\mathbf{0 . 6 4 1}$ & 0.034 \\
LOP & $\mathbf{0 . 6 7 0}$ & 0.038 & 0.030 \\
NSE & $\mathbf{0 . 1 9 4}$ & 0.046 & 0.084 \\
LFR & $\mathbf{0 . 4 0 3}$ & 0.013 & 0.192 \\
DFR & $\mathbf{0 . 3 8 6}$ & 0.000 & 0.087 \\
PCG & $\mathbf{0 . 3 7 4}$ & 0.004 & 0.008 \\
PFF & 0.144 & 0.203 & $\mathbf{0 . 3 1 4}$ \\
Proper value & 3.227 & 1.890 & 1.533 \\
Variability $(\boldsymbol{\%})$ & 26.890 & 15.749 & 12.773 \\
\% cumuli & 26.890 & 42.639 & 55.413 \\
\hline
\end{tabular}

Number of days 50\% flowering (DFL) ; number of fruits per plant (NFR); Petiole length (LPE); Leaf length (LOL); Plant height (HPL); Stem Diameter (DIT); Petal lenght (LOP); Number of sepal (NSE); Length of fruit (LFR); Diameter of fruit (DFR); Weight of 100 seeds (PCG); Leaves biomass (PFF).

\section{Dendrogramm}

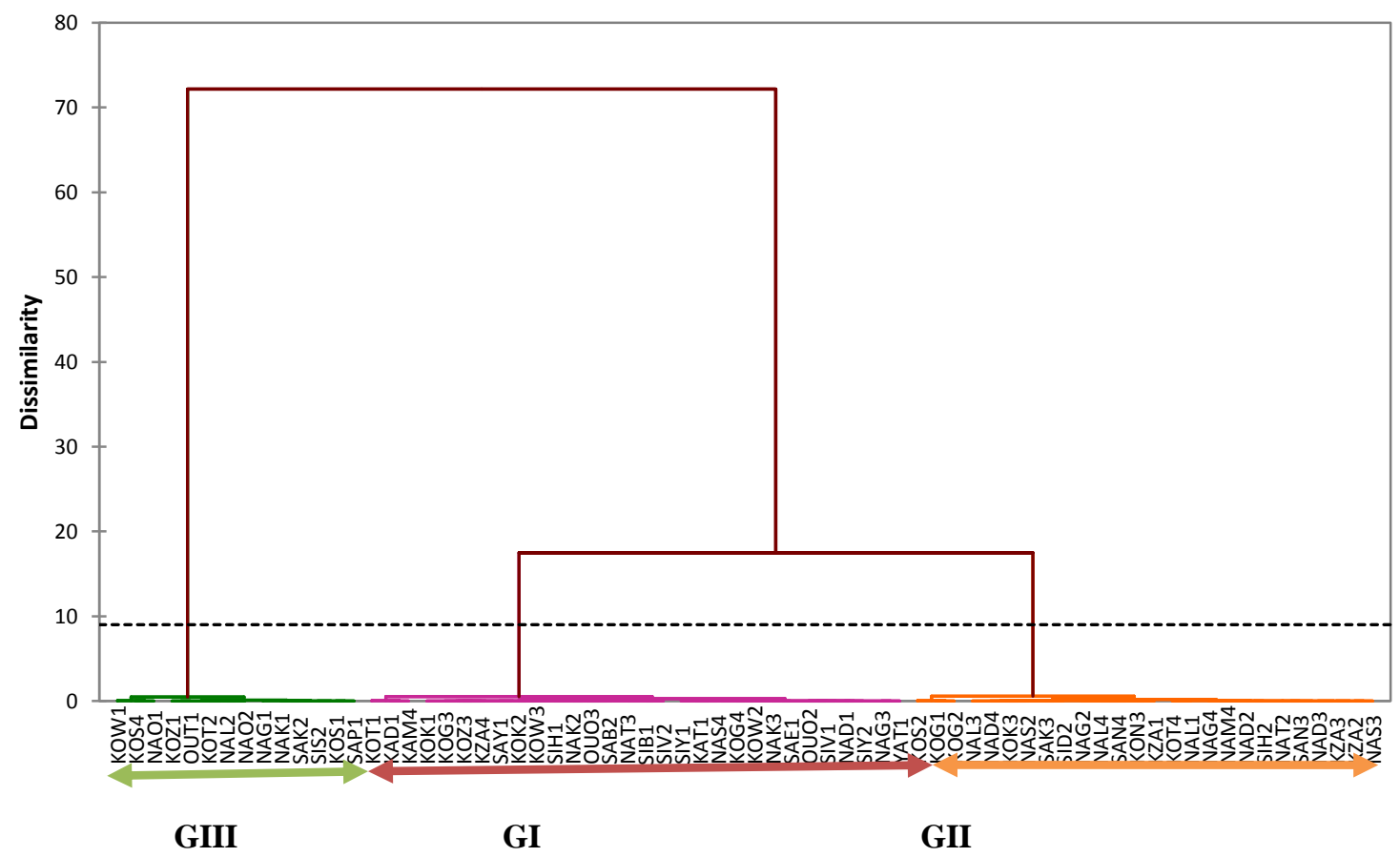

Figure 3: Dendrogram of Dissimilarity among 70 accessions of $H$. cannabinus using Ward's Minimum Variance Method of Cluster Analysis. 
N. V. KABRÉ et al. / Int. J. Biol. Chem. Sci. 13(4): 1903-1917, 2019

Table 7: Evaluation of the average performance of the 4 groups by the Newmann Keuls test.

\begin{tabular}{|c|c|c|c|c|c|c|}
\hline \multirow[b]{2}{*}{ VAR. } & \multicolumn{3}{|l|}{ Groups } & \multirow[b]{2}{*}{$\mathbf{R}^{2} \%$} & \multirow[b]{2}{*}{ F.Fisher } & \multirow[b]{2}{*}{$\operatorname{Pr}>\mathbf{F}$} \\
\hline & Group 1 & Group 2 & Group 3 & & & \\
\hline DFL & $80.52 \mathrm{~A}$ & $76.35 \mathrm{~B}$ & $78.85 \mathrm{AB}$ & 3.5 & 3.69 & 0.027 \\
\hline NFR & $51.34 \mathrm{~B}$ & $83.21 \mathrm{~A}$ & $85.33 \mathrm{~A}$ & 54.1 & 121.40 & $<0.0001$ \\
\hline LPE & $19.65 \mathrm{~A}$ & $19.91 \mathrm{~A}$ & $19.66 \mathrm{~A}$ & 0.2 & 0.19 & 0.824 \\
\hline LOL & $13.96 \mathrm{~A}$ & $13.94 \mathrm{~A}$ & $13.80 \mathrm{~A}$ & 0.1 & 0.081 & 0.922 \\
\hline HPL & $2.67 \mathrm{~A}$ & $2.72 \mathrm{~A}$ & $2.76 \mathrm{~A}$ & 0.3 & 0.35 & 0.706 \\
\hline DIT & $3.06 \mathrm{~A}$ & $3.25 \mathrm{~A}$ & $3.13 \mathrm{~A}$ & 1.6 & 1.66 & 0.192 \\
\hline LOP & $6.76 \mathrm{~A}$ & $7.16 \mathrm{~A}$ & $7.13 \mathrm{~A}$ & 2.8 & 3.00 & 0.052 \\
\hline NSE & $7.50 \mathrm{~A}$ & $7.47 \mathrm{~A}$ & $7.42 \mathrm{~A}$ & 0.2 & 0.18 & 0.834 \\
\hline LFR & $2.24 \mathrm{~A}$ & $2.23 \mathrm{~A}$ & $2.20 \mathrm{~A}$ & 0.1 & 0.06 & 0.933 \\
\hline DFR & $1.59 \mathrm{~A}$ & $1.50 \mathrm{~B}$ & $1.52 \mathrm{AB}$ & 4.4 & 4.77 & 0.009 \\
\hline PCG & $2.77 \mathrm{~B}$ & $2.97 \mathrm{~A}$ & $2.84 \mathrm{AB}$ & 4.7 & 5.095 & 0.007 \\
\hline PFF & $577.02 \mathrm{C}$ & 1681.68B & $3577.66 \mathrm{~A}$ & 97.5 & 3946.34 & $<0.0001$ \\
\hline
\end{tabular}

Number of days 50\% flowering (DFL ); number of fruits per plant (NFR); Petiole length (LPE); Leaf length (LOL); Plant height (HPL); Stem Diameter (DIT); Petal lenght (LOP) ; Number of sepal (NSE); Length of fruit (LFR); Diameter of fruit (DFR); 100 seeds Weight (PCG); Leaves biomass (PFF). F: F of Fisher; R $^{2}$ : coefficient of determination. 
N. V. KABRÉ et al. / Int. J. Biol. Chem. Sci. 13(4): 1903-1917, 2019

Table 8: Evaluation of the genetic parameters of the accessions of $H$. cannabinus of Burkina Faso.

\begin{tabular}{|c|c|c|c|c|c|c|c|c|c|c|c|}
\hline Variables & SMG & SME & VG & VP & $\mathbf{H}^{2}(\%)$ & $\sqrt{ } \mathbf{V G}$ & $\sqrt{ } \mathbf{V P}$ & $\operatorname{GCV}(\%)$ & $\operatorname{PCV}(\%)$ & GA & $\operatorname{GAx}(\%)$ \\
\hline DFL & 221.31 & 40.89 & 60.14 & 73.77 & 81.52 & 7.75 & 8.59 & 9.86 & 10.92 & 14.42 & 18.34 \\
\hline NFR & 1157.6 & 149.1 & 336.17 & 385.87 & 87.12 & 18.33 & 19.64 & 26.23 & 28.10 & 35.25 & 50.43 \\
\hline LPE & 9.76 & 5.7 & 1.35 & 3.25 & 41.60 & 1.16 & 1.80 & 5.89 & 9.13 & 1.55 & 7.83 \\
\hline LOL & 7.75 & 2.97 & 1.59 & 2.58 & 61.68 & 1.26 & 1.61 & 9.07 & 11.55 & 2.04 & 14.67 \\
\hline LAL & 6.03 & 3.24 & 0.93 & 2.01 & 46.27 & 0.96 & 1.42 & 8.89 & 13.07 & 1.35 & 12.45 \\
\hline HPL & 0.42 & 0.27 & 0.05 & 0.14 & 35.71 & 0.22 & 0.37 & 8.28 & 13.86 & 0.28 & 10.20 \\
\hline DIT & 0.4 & 0.33 & 0.02 & 0.13 & 17.50 & 0.15 & 0.37 & 4.86 & 11.63 & 0.13 & 4.19 \\
\hline LOP & 2.14 & 0.8 & 0.45 & 0.71 & 62.62 & 0.67 & 0.84 & 9.57 & 12.10 & 1.09 & 15.61 \\
\hline LAP & 0.96 & 0.58 & 0.13 & 0.52 & 0.01 & 0.36 & 62.63 & 9.34 & 16.72 & 0.00 & 0.11 \\
\hline NSE & 0.6 & 0.44 & 0.05 & 0.20 & 26.67 & 0.23 & 0.45 & 3.09 & 5.99 & 0.25 & 3.29 \\
\hline LFR & 0.32 & 0.3 & 0.01 & 0.11 & 6.25 & 0.08 & 0.33 & 3.68 & 14.71 & 0.04 & 1.89 \\
\hline DFR & 0.04 & 0.03 & 0.00 & 0.01 & 25.00 & 0.06 & 0.12 & 3.75 & 7.50 & 0.06 & 3.86 \\
\hline PCG & 0.52 & 0.01 & 0.17 & 0.19 & 98.08 & 0.41 & 0.42 & 14.42 & 14.56 & 0.84 & 29.41 \\
\hline PFI & 891.2 & 13.99 & 292.40 & 297.07 & 98.43 & 17.10 & 17.24 & 25.08 & 25.28 & 34.95 & 51.25 \\
\hline PFF & 3833848 & 8074 & 1275258.00 & 1277949.33 & 99.79 & 1129.27 & 1130.46 & 71.16 & 71.23 & 2323.85 & 146.43 \\
\hline
\end{tabular}

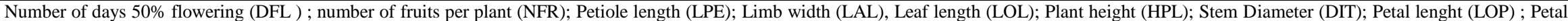

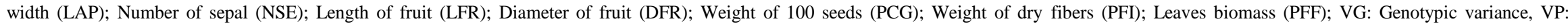
Phenotypic variance $\mathrm{H}^{2}$ : Heritability, GCV: Genotypic coefficient of variation, PCV: Phenotypic coefficient of variation, GAx: Genetic advance expected. 


\section{DISCUSSION}

This study revealed the existence of a high morphological variability within accessions of Hibiscus cannabinus grown in Burkina Faso. The higher coefficients of variation values of studied characters give an idea of this variability. The most variable characters are the number of fruits $(\mathrm{CV}=31.52 \%)$ and leaves biomass $(\mathrm{CV}=71.25 \%)$. According to Aljane and Ferchichi (2007), a high value of the coefficient of variation indicates the heterogeneity of the studied genetic material. So the studied accessions are heterogeneous for the variables, number of fruits and the leaves biomass. Six morphotypes have been identified on the basis of the stem color compared to three morphotypes identified according to farmers's nomenclature during ethnobotanical investigation. This difference could be resulted from the interpretation of the morphotypes coloration by the farmers. In fact, farmers don't distinguish the red color and violet, the black color and purple. The prevalence of the green morphotype that is observed within the cultivars may be explained by peasants' farming method which is more oriented by the preference of the green color. Indeed, the leaves of the green morphotype are more valued for its food value and its fibers are more suitable for the stringing (Kabré et al., 2017). The performances of the limb length $(13.9 \mathrm{~cm})$, limb width $(10.85 \mathrm{~cm})$, petal length $(6.98 \mathrm{~cm})$ and $50 \%$ flowering days (78 days), are close to those found by Faruq et al. (2013) on Malaysian morphotypes. However the diameter of the stem $(1.4 \mathrm{~cm})$ and the height of the plant $(2.1 \mathrm{~m})$, measured by Faruq et al. (2013) were, however, smaller than those observed in our study. Indeed the cumbersome span of the plant vegetative part varies from a country to another and could be influenced by photosensitivity and climate type according to Mahieu et al. (2003). These authors argue that H. cannabinus has a better growth in the tropical and subtropical zones, an altitude of no less than $500 \mathrm{~m}$ above sea level. This is due to the fact that it adjusts itself to both hot and humid climate.
The study also revealed interesting correlations between several characters related to the plant height (HPL) and the stem diameter (DTI) on the one hand and between the plant height and the dry fibers weight on the other hand. These correlations show that plants of large size have a well-developed stem to assure its stability and also produce much fiber. Accessions organization in three distinct groups without referring to their origin could indicate the existence of diversity within accessions of the original population. This is due to the perpetual plant material exchanges between the farmers of different or neighboring localities, revealed during ethnobotanical investigation (Kabré et al., 2017). However, the morphological diversity between groups showed that there are possibilities of a genetic improvement of the species; either by direct selection within every group or by hybridization between groups. For a possible selection of Hibiscus cannabinus producing more leaves, seeds and fibers, group 3 is more reliable because it allows genitors' choice for new creation of varieties meeting producers' needs. Moreover, the high distance between groups $(820-049 ; 1117-717$ and 1937-766 for between 1-3; 1-2 and 2-3 respectively) would facilitate the transgressive segregation, because the greater the genetic distance, the more heterosis in the offspring can be observed. The testing of the genotypic coefficient of variation (GCV) and heritability $\left(\mathrm{H}^{2}\right)$ provides interesting information on the choice of the parents to be hybridized in order to get the desired traits (Ibrahim et al., 2006). Thus, the identification of characters to be improved genetically is based on the variability and heritability of the characters. A good knowledge of the genetic parameters is thus necessary for the choice of the optimal selection criteria (Merour et al., 2008). In order to understand whether the observed variation was due to genetic factors, the genetic parameters were estimated. For the studied characters, phenotypic coefficient of variation (PCV) is higher than genotypic coefficient of variation (GCV) for all the characters. But the differences between them are low, indicating a significant genetic 
control on the expression of the studied characters (Lakshmana et al., 2009). Similar results were reported on Burkina Faso sweet grains sorghum (Sawadogo et al., 2014), on millet (Drabo et al., 2013; Govindaraj et al., 2011; Hosseini et al., 2012) and on rice. According to the classification of Sumathi et al. (2010), the genotypic and phenotypic coefficients of variation are low when they are below $10 \%$, moderate when they are between 11 and 20\%; and higher when they are above $20 \%$. So, the number of sepals, petiole length and fruit diameter have lower PCV and GCV. These coefficients of variation revealed the extent of the variability but the heritability allows knowing the proportion of variability transferable to the progeny. About all studied characters expressed high heritability $\left(\mathrm{H}^{2}>20 \%\right)$. Danquah and Ofori (2012) got the same result with Ghana eggplants, Vetriventhan and Nirmalakumari (2007) on millet, Ali et al. (2012) and Nebié (2014) on sorghum. This high heritability of characters confirms the low influence of environmental factors on characters expression. Thus, the phenotype allows a good prediction of genotype accessions (Visscher et al., 2008). That means that the contribution of genotypes to the expression of characters is important. Heritability alone doesn't permit to predict if the selection brings a substantial improvement. Nevertheless, both heritability $\left(\mathrm{H}^{2}\right)$ and genetic progress (GAx) evaluation can bring more reliable information (Govindaraj et al., 2011; Drabo et al., 2013). So heritability and the huge genetic progress (GAx) that have been observed, the number of days 50\% flowering, the number of fruits, the limb length and width, the plant height, the petal length, the 100 seeds weight, the dry fibers weight and the leaves biomass, show large genetic effects of additive type in these characters determination (Kashif et al., 2003). Thus a direct selection method for the enhancement of $H$. cannabinus is possible for these traits.

\section{Conclusion}

This study revealed important agromorphological diversity within accessions of $H$. cannabinus in Burkina Faso. This variability is perceptible on all the studied characters and much more on the number of fruits, stem diameter, plant height, leaves biomass and dry fibers weight. These characters presented interesting relationships between them, indicating that the improvement of a single character would cause that of the others. The study also revealed a structuring of $H$. cannabinus accessions into three (3) agro-morphological groups without reference to their origin whose parameters such as number of fruits, dry fibers weight and leaves biomass are those that differentiate them. Morphological group 3 accessions have the best agronomic performances in relation to those of groups 1 and 2. The study, besides, shows more important genetic control on characters expression proved by high heritability and low extent difference between phenotypical and genotypical coefficients of variation. Besides heritability and genetic progress values suggests that most quantitative characters of $H$. cannabinus would be controlled by additive genes. Thus a genetic improvement can be considered from the variability highlighted in this study.

\section{COMPETING INTERESTS}

Authors have declared that no competing interests exist.

\section{AUTHORS'S CONTRIBUTION}

This work was carried out in collaboration between all the authors. NVK wrote the draft of the manuscript, performed the statistical analysis and the literature searches. BS, MK and ZK read and amend the manuscript and also managed the analyses of the study. RKN gave practical advice for the activities designed. PB-K wrote the research protocol, gave practical advice for the activities designed, read and enhanced the quality of the final manuscript and financially supported the study. All the authors read and approved of the final manuscript. 


\section{ACKNOWLEDGEMENTS}

We address our heartfelt acknowledgements to all our brave peasants for their welcoming, collaboration, and contribution to the conservation of Hibiscus cannabinus diversity.

\section{REFERENCES}

Ali HI, Mahmoud KM, Amir AA. 2012. Estimation of Genetic Variability, Heritability and Genetic Advance in Grain Sorghum Population. AmericanEurasian J. Agric. \& Environ. Sci., 12(4): 414-422. DOI : http://www.idosi.org/aejaes/jaes12(4)12/ 1.pdf.

Aljane F, Ferchini A. 2007. Caractérisation et évaluation de six cultivars du caprifiguier (Ficus carica L.) en Tunisie. Plant Genetic Resource Newsletter, 151: 22-26.

DOI : https://dialnet.unirioja.es/servlet/articulo ? codigo $=6298679$.

Assefa K, Tefera H, Merker A, Kefyalew T, Hundera F. 2001. Variability, heritability and genetic advance in phenomorphic and agronomic traits of Tef [Eragrostis tef (Zucc.) Trotter] germplasm from eight regions of Ethiopia. Hereditas, 134(2): 103-113.

Bermúdez-Soto MJ, Tomás-Barberán FA, García-Conesa MT. 2007. Stability of polyphenols in chokeberry (Aronia melanocarpa) subjected to in vitro gastric and pancreatic digestion. Food Chemistry, 102(3): $\quad 865-874 . \quad$ DOI : https://doi.org/10.1016/j.foodchem.2006. 06.025 .

Danquah JA, Ofori K. 2012. Variation and correlation among agronomic traits in 10 accesssions of garden eggplant (Solanum gilo Raddi) in Ghana. International Journal of Science and Nature, 3(2): 373-379.

Drabo I, Zangre GR, Sawadogo M, Ouedraogo M. 2013. Genetic Variability and Estimates of Genetic Parameters in Burkina Faso's Pearl Millet Landraces. International Journal of Agriculture and Forestry, 3(7): 367-373.
Faruq G, Alamgir MA, Rahman MM, Motior MR, Zakaria HP, Marchalina P, Mohamed NA. 2013. Morphological characterization of kenaf (Hibiscus cannabinus L.) In: Malaysian tropical environment using multivariate analysis. The J. Ani. Plant Sci., 23(1): 60-67.

Govindaraj M, Selvi B, Rajarathinam S, Sumathi P. 2011. Genetic Variability and Heritability of Grain Yield Components and Grain Mineral Concentration in India's Pearl Millet (Pennisetum glaucum (L) R. Br.) Accessions. African Journal of Food, Agriculture, Nutrition and Development, 11(3).

Hosseini SJ, Sarvestani ZT, Pirdashti H, Afkhami A, Hazrati S. 2012. Estimation of heritability and genetic advance for screening some rice genotypes at salt stress conditions. International journal of Agronomy and Plant Production, 3(11): 475-482.

Ibrahim SM, Hussein AK. 2006. Variability, heritability and genetic advance in some genotypes of roselle (Hibiscus sabdariffa L.). World J. Agric. Sci., 2: 340-345.

Johnson HW, Robinson HF, Comstock RE, 1955. Estimates of genetic and environmental variability in Soybeans. Agronomy Journal, 47(7): 314-318.

Nikodème VK, Zakaria K, Mariam K, Boureima S, Ernest RT, Nerbéwendé S, Pauline BK. 2017. Farmers' Knowledge and Interest Traits of Hibiscus cannabinus Grown in Burkina Faso. Journal of Agriculture and Ecology Research International, 15(4): 1-8.

Kashif M, Ahmad J, Chowdhry MA, Perveen K. 2003. Study of Genetic Architecture of Some Important Agronomic Traits in Durum Wheat (Triticum durum). Asian Journal of Plant Sciences, 2(9): 708-712.

Lakshmana D, Biradar BD, Ravikumar RL. 2009. Genetic variability studies for quantitative traits in a pool of restorers and mainteners lines of pearl millet (Pennisetum glaucum (L.). Karnataka J. Agric. Sci., 22(4): 881-882.

Mahieu PJ, Oplinger ES, Putnam DH. 2003. Kenaf. In: Alternative Field crops 
Manual.

http://www.corn.agronomy.wisc.edu/FIS

C/Alter natives /Kenaf.htm.Merour I., Bernard E.

Merour I, Bernard E, Canario L, Bidanel J.P. 2008. Comment la sélection génétique peut améliorer la survie des porcelets en allaitement. TechniPorc, la revue technique de l'IFIP, 31(2): 23-24.

Millogo-Rasolodimby J. 2001. L'Homme, le climat et les ressources alimentaires végétales en périodes de crise de subsistance au cours du 20ème siècle au Burkina Faso. Thèse Doct., Univ. Ouagadougou. 2001; 249.

Nebié B. 2014. Diversité génétique d'une collection de sorgho a tige sucrée [Sorghum bicolor (L.) Moench] du Burkina Faso. Thèse Unique, Université de Ouagadougou (Burkina Faso) 118p.

Sawadogo N, Nanema KR, Bationo P, Traoré RE, Nebié B, Tiama D, Sawadogo M, Zongo JD. 2014b. Évaluation de la diversité génétique des sorghos à grains sucrés (Sorghum bicolor (L.) Moench) $\mathrm{du}$ Nord du Burkina Faso. Journal of Applied Biosciences, 84(1): 7654-7664.

Sumathi P, Sumanth M, Veerabadhiran P. 2010. Genetic variability for different biometrical traits in pearl millet genotypes (Pennisetum glaucum LR BR.). Electronic Journal of Plant Breeding, 1(4): 437-440.

Thiombiano A, Kampmann D. 2010. Atlas de la biodiversité de l'Afrique de l'Ouest, Tome II: Burkina Faso, Ouagadougou et Frankfurt/Main. Vetriventhan M. and Nirmalakumari A., 2007.

Vetriventhan M, Nirmalakumari A. 2007. Studies on Variability Parameters in Pearl Millet (Pennisetum glaucum (L.) R. Br.). Madras Agricultural Journal, 94(1/6): 118-120.

Visscher P.M, William G.H, Naomi R.W. 2008. Heritability in the genomics eraconcepts and misconceptions. Nature Reviews Genetics, 9(4): 255-266 pp. 